\title{
Economic Assessment of Flood Control Facilities under Climate Uncertainty: A Case of Nakdong River, South Korea
}

\author{
Kyeongseok Kim ${ }^{1, *(1)}$ and Ji-Sung Kim ${ }^{2}$ (10) \\ 1 School of Civil \& Environmental Engineering, Yonsei University, Seoul 03277, Korea \\ 2 Hydro Science and Engineering Research Institute, Korea Institute of Civil Engineering and \\ Building Technology, Goyang-Si 10223, Korea; jisungk@kict.re.kr \\ * Correspondence: kim.ks@yonsei.ac.kr; Tel.: +82-2123-7940
}

Received: 6 November 2017; Accepted: 24 January 2018; Published: 25 January 2018

\begin{abstract}
Climate change contributes to enhanced flood damage that has been increasing for the last several decades. Understanding climate uncertainties improves adaptation strategies used for investment in flood control facilities. This paper proposes an investment decision framework for one flood zone to cope with future severe climate impacts. This framework can help policy-makers investigate the cost of future damage and conduct an economic assessment using real options under future climate change scenarios. The proposed methodology provides local municipalities with an adaptation strategy for flood control facilities in a flood zone. Using the proposed framework, the flood prevention facilities in the Nakdong River Basin of South Korea was selected as a case study site to analyze the economic assessment of the investments for flood control facilities. Using representative concentration pathway $(\mathrm{RCP})$ climate scenarios, the cost of future flood damage to 23 local municipalities was calculated, and investment strategies for adaptation were analyzed. The project option value was determined by executing an option to invest in an expansion that would adapt to floods under climate change. The results of the case study showed that the proposed flood facilities are economically feasible under both scenarios used. The framework is anticipated to present guidance for establishing investment strategies for flood control facilities of a flood zone in multiple municipalities' settings.
\end{abstract}

Keywords: climate change; flood control; real options analysis; economic assessment; adaptation

\section{Introduction}

Climate change (CC) contributes to severe environmental risks to the world [1]. Because CC alters current precipitation patterns, heavier precipitation events have occurred in a number of regions throughout the last 60 years [2]. The risks caused by changes in precipitation include increased flooding and drought. The impact of CC arises over both short-term and long-term periods [3], and losses and costs related to global and local flood damage have been increasing for the last several decades [2]. The destruction and insufficient capacity of flood control facilities (FCFs) due to flooding events require not only urgent recovery, but also adaptation. However, conducting economic feasibility studies of adaptation for FCFs is not easy because uncertainties are associated with future CC and economic growth [4]. Thus, planning adaptation related to FCF should take into account changes in future climate patterns and economic uncertainty.

There have been numerous attempts to develop economic assessment techniques for adaptation investment to CC. Arnbjerg-Nielsen and Fleischer [5] used the net present value (NPV) method to assess the feasibility of urban drainage facilities considering adaptation to long-term sea-level rise, using an analysis of flood damage costs. Zhou et al. [6] proposed a framework that provided 
an economic assessment of pluvial flood risk, considering CC, and calculated the expected annual damage from future extreme precipitation, using a cost-benefit analysis with NPV. Olsen et al. [7] compared methods of calculating expected annual damage in urban pluvial flood risk assessments in Denmark and showed that estimating the expected annual damage correlated with degrees of flood risk. Ha et al. [8] proposed a reliability-based economic assessment of adapting infrastructure to CC to estimate the damage costs from climate-related risks. From this, decision-makers can apply a cost and benefit estimation of an adaptation project using CC scenario analysis.

Traditional economic assessment methods, such as discount cash flow (DCF) estimate investments using NPV, which is the most widely-used decision-making tool for various investment projects, but not for highly volatile investments [9]. In the case of an investment with options, real option analysis (ROA) is a novel method in investment decision-making that more precisely evaluates projects, as compared to traditional methods, such as DCF [10]. ROA considers managerial flexibility and the volatility of a project's cash flow [11-13]. Recent studies on economic assessment for adaptation investment under CC recommend ROA as a methodology that can not only capture uncertainties but also evaluate economic feasibility. Ryu et al. [14] implemented ROA, using delay and abandon options, to assess FCF for the Yeongsan River Basin in South Korea and suggested the priority ranking of adaptation methods by traditional DCF and ROA. Kontogianni et al. [15] showed that ROA supported the assessment of costs associated with sea-level rise and adaptation benefits under climate uncertainty in Greece, by using an option to defer. Kim et al. [16] proposed a real options-based decision-making model to estimate the economic feasibility of adaptation projects in urban areas, using representative concentration pathway (RCP) climate scenarios. Gersonius et al. [17] used a real options analysis for urban drainage adaptation in England, using the volatility of rainfall intensity and CC modeling data. Woodward et al. [18] employed a flood risk analysis to evaluate a flood system in the Thames Estuary in London, England, using real options, under the uncertainty of sea-level rise. Harrison et al. [19] used rainfall patterns to assess the financial viability of an existing hydropower plant and applied CC scenarios to analyze project risks. In a review of the related literature, there were no studies that investigated flood adaptation for multiple local municipalities' areas in a flood zone, using a real option approach.

Many studies have dealt with issues related to the feasibility of adaptation investment, using ROA. They have used historical climate data or future CC scenarios to estimate future climate information. These studies have achieved the advanced investment decisions method for FCF. However, historic data is not a good basis for ROA when climate futures are very different from historic trends. An extreme weather event simultaneously affects flood damage in many local municipal areas. Thus, a response of mutual cooperation is needed in cases where a river crosses government boundaries. It is not easy for local municipalities with one flood source to combine resources, in terms of flood disaster prevention facilities. Investment in adaptation measures depends on both the extent of flood damage for different municipalities and the investment cost for FCF. In addition, climate-related risks will continue to increase with a rise in natural disasters, as compared to the past [2]. So, an adaptation strategy of FCF should be derived, not from past climate information, but from the future, using scenarios across a range of future climate conditions. Thus, we propose a methodology that provides a strategy for FCF adaptation for multiple local municipalities within one flood zone. The proposed methodology can consider future CC impacts in a flood zone and determine the economic feasibility of FCFs using ROA and CC scenarios. The proposed methodology could help policy-makers develop adaptation strategies for sustainable FCFs under CC.

If policy makers are able to estimate future damage costs for each municipality, they can develop sustainable adaptation strategies to CC. Over the past decade, South Korea has incurred costs of about US\$550 million from damage every year, due to typhoons, river floods, and heavy rains [20]. Some rivers in South Korea pass through more than 20 municipalities. Often the villages nearest the river suffer from floods. Unexpected floods, triggered by extreme precipitation, cause serious damage to nearby residents' properties and lives. Local municipalities need new adaptation strategies for a flood 
zone, to cope with the increasing impact of CC. The strategies should deal with investment costs, implementation time, and priority. The proposed framework can provide the investment priority and costs for multiple local municipalities in a flood zone under future CC.

We suggest a framework for making investment decisions on adaptation to CC regarding FCFs for multiple local municipalities within a flood zone. The proposed framework suggests ROA to cope with future floods, projected by RCP climate scenarios, that are representative concentration pathways for emissions, that are based on different assumptions affecting those pathways across low to high emissions levels. This framework provides a method to estimate economic losses from future floods under RCP climate scenarios and the economic feasibility of investments in FCFs under CC. The RCPs project the impacts of CC. The scenarios are composed of four different pathways, including a preindustrial level scenario (RCP2.6), two intermediate scenarios (RCP4.5 and RCP6.0), and an extreme greenhouse gas (GHG) emission scenario (RCP8.5) [2,21].

Figure 1 shows the investment decision framework of a flood zone for a suggested adaptation investment to climate uncertainty. The first step is to define a flood zone that includes municipalities near a river that have suffered from floods. Within this, we need to identify flood sources, including precipitation, melting ice, and sea-level rise. The second step is to define future scenarios that include CC scenarios. We estimate the extent of flood risk, using future CC scenarios. The third step is to estimate the cost of damage under future conditions. Historical information regarding flood damage helps us estimate future damage with economic factors. The fourth step is to identify the target flood control criteria with consideration to future damage costs under the selected CC scenarios. Local municipalities reduce flood risk by upgrading FCF capacity, considering future CC. The return period of a flood event should be increased, to reduce the level of damage to the target level. The fifth step is to conduct ROA to analyze the economic feasibility of FCFs, aiming to adapt to future CC. Using a binomial lattice approach, we calculated the adaptation profits for investment decisions under each climate scenario. The sixth step is to develop adaptation strategies that suggest priorities and investment costs for local municipalities. A detailed explanation of the proposed framework is presented in Section 2.

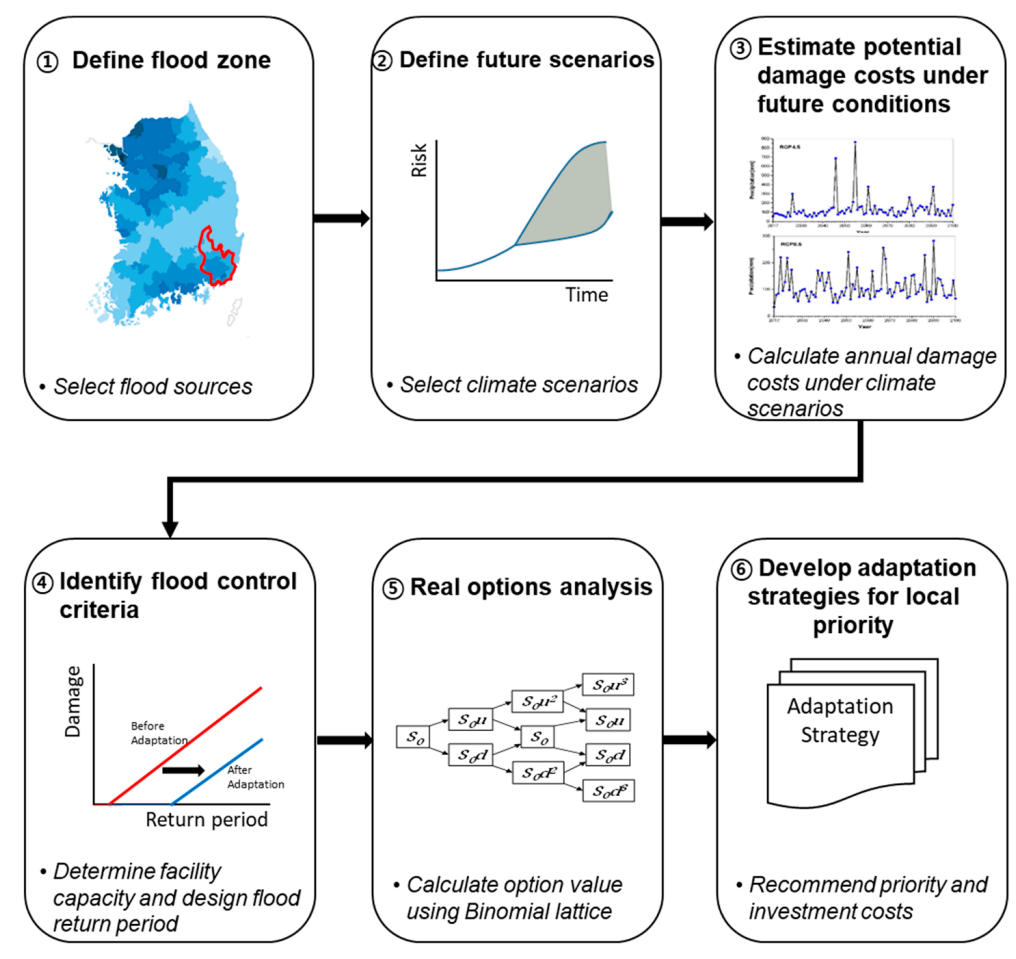

Figure 1. Investment decision framework of a flood zone. 


\section{Methods}

Climate-related risks result in future damage costs from floods in cases where the existing FCFs cannot prevent flooding. The level of damage can be estimated using CC scenarios to project future climate-related risks. To estimate the damage costs of floods, we use past information to show the relationship between the damage and the return period of the floods. Future damage costs are calculated by assuming a log-linear relationship between the damage cost of a flood event and the corresponding return period [6,7]. The future damage costs will be similar to historical damage costs for the same level of damage. However, the damage costs are increased with the rate of inflation. Equation (1), developed by Kim et al. [16], estimates damage costs of a flood event, using the log-linear relationship.

$$
D_{i}=a \ln (R)\left(1+r_{i}\right)^{i-1}
$$

where $D_{i}$ is the future damage cost in year $i, R$ is the return period of the flood event, $a$ is a constant based on the historical data of extreme weather events, and $r_{i}$ is the inflation rate.

Because of climate uncertainty, it is not easy to invest in the FCFs of a local government, to protect against future flood events. ROA can be used to analyze the economic feasibility of an investment under CC [22]. Decision-makers can use managerial flexibility to hedge future uncertainties in climate. The benefit of FCF investment is the reduced future climate-related risk through the adaptation measure [8]. Climate scenarios inform climate-related risks. To capture climate risk, we estimate the volatility of benefits arising from FCF investment under CC. The volatility $(\sigma)$ can be obtained by applying the logarithmic cash flow returns approach to the cash flow of future returns by the FCF investment. The volatility is calculated by Equation (2) [23].

$$
\sigma=\sqrt{\frac{1}{n-1} \sum_{i=1}^{n}\left(x_{i}-\bar{x}\right)^{2}}
$$

where $n$ is the number of cash flow returns, $x_{i}$ is the individual cash flow returns, and $\bar{x}$ is the average of $x_{i}$. In general, the data is converted into annual data, using the equation $\sigma\left(T_{2}\right)=\sigma\left(T_{1}\right) \times \sqrt{T_{2} / T_{1}}$ [24], where $\sigma\left(T_{2}\right)$ and $\sigma\left(T_{1}\right)$ are the volatilities of the time steps $T_{2}$ and $T_{1}$, respectively.

Managerial flexibility has the right to exercise options in a project [25]. If climate impacts are expected to change in the future, the investor may execute options for adaptation to CC. By executing options to abandon or expand investments, in order to reduce future damage, decision-makers have an opportunity to reduce risks and improve project value.

An underlying asset value adopts the present value of the most likely cash flow for an ROA [26]. The present value of the underlying asset $\left(S_{0}\right)$ is estimated using Equation (3), and NPV can be obtained by Equation (4).

$$
\begin{gathered}
S_{0}=\sum_{i=1}^{n} \frac{D_{i}}{\left(1+r_{d}\right)^{i-1}} \\
\mathrm{NPV}=\sum_{i=1}^{n} \frac{x_{i}-c_{i}}{(1+n)^{i-1}}
\end{gathered}
$$

where $n$ is the project period of the FCF, $r_{d}$ is the discount rate, and $c_{i}$ is the investment cost at year $i$.

The option values are calculated by the formulation of the up $(u)$ and down $(d)$ movement per node in the binomial lattice approach, calculated by Equations (5) and (6), respectively [23].

$$
\begin{gathered}
u=e^{\sigma \sqrt{\Delta t}} \\
d=\frac{1}{u}
\end{gathered}
$$


The risk-neutral probability $(q)$ and option value $(C)$ are represented by Equations (7) and (8), respectively [24,27].

$$
\begin{gathered}
q=\frac{\left(e^{r_{f} t}-d\right)}{u-d} \\
C=e^{-r_{f} t}\left[q C_{u}+(1-q) C_{d}\right]
\end{gathered}
$$

where $\Delta t$ is a time-step increment, $r_{f}$ is the risk-free interest rate, $C_{u}$ is the option value if the underlying asset value $(S)$ increases, and $C_{d}$ is the option value if $S$ decreases. ROA investigates a project value by the binomial lattice approach, which effectively visualizes the results using risk-neutral probability [22]. The option value $(C)$ of each node represents the value maximization, with options to try to lessen climate uncertainties, such as deferral, abandonment, expansion, and growth.

\section{A Case Study of the Nakdong River Basin}

\subsection{Project Description}

The Intergovernmental Panel on Climate Change (IPCC) [2] reported that precipitation is expected to be heavier and more frequent in many regions over the next few decades. The Korea Meteorological Administration reported that annual precipitation in South Korea is anticipated to increase by $16 \%$, from 2000 to 2100, under the RCP8.5 scenario and by 17.6\% under RCP4.5 [28]. Nakdong River is located in the southeast region of South Korea and passes through 23 municipalities (Figure 2). The length of the river is $521 \mathrm{~km}$, and the basin where floods frequently occur during the summer season is $23,817 \mathrm{~km}^{2}$ [29]. A number of reservoirs, detention basin, drainage systems and flood control dams have been installed to prevent floods in the Nakdong River Basin. These FCFs are those widely-used for flood control in river basins in South Korea. However, flooding in the Nakdong River Basin has resulted in damages of US\$2.58 billion, from 1986 to 2015 [20]. The ROA can be used to assess the robustness and flexibility of a number of FCFs and other flood risk reduction options that can reduce exposure to future flooding under changing climate conditions. The main cause was heavy rainfall that exceeded the design standards of existing FCFs. The design of FCFs should follow government regulations, which meet the 200-year return period of flood, based on a cumulative $48 \mathrm{hr}$ of rainfall [30]. However, precipitation will increase over time, and thus, the capacity will be insufficient to cope with future floods under CC. Local municipalities have tried to prevent floods by implementing adaptation measures that lessen flood-related risks, but these programs have suffered from budget limitations. ROA for investment decisions in FCFs under CC was applied to establish future adaptation strategies for the case study. The investment decision framework of the flood zone will deal with a case study on 23 municipalities of the Nakdong River Basin and demonstrate the validity of the framework using ROA. The 23 municipalities are Goryeong-gun, Gumi-si, Gimhae-si, Dalseo-gu in Daegu, Dalseong-gun in Daegu, Mungyeong-si, Miryang-si, Gangseo-gu in Busan, Buk-gu in Busan, Sasang-gu in Busan, Saha-gu in Busan, Sangju-si, Seongju-un, Andong-si, Yangsan-si, Yecheon-gun, Uiryeong-gun, Uiseong-gun, Changnyeong-gun, Changwon-si, Chilgok-gun, Haman-gun, and Hapcheon-gun.

Figure 3 shows the 10-year sum of flood damage costs within the 23 local municipalities of the Nakdong River Basin between 1971 and 2010 [20]. Flood damage has significantly increased throughout those 40 years. If local municipalities do not implement various adaptation measures to cope with future floods, the intensity of damage will worsen significantly over time. However, adaptation strategies for investments in FCFs place a burden on local municipalities, due to the lack of financial support for such projects. Herein, we present guidance for establishing adaptation plans for the case study. Using the proposed framework, we investigate future damage costs and conduct an economic assessment using ROA under future CC. 


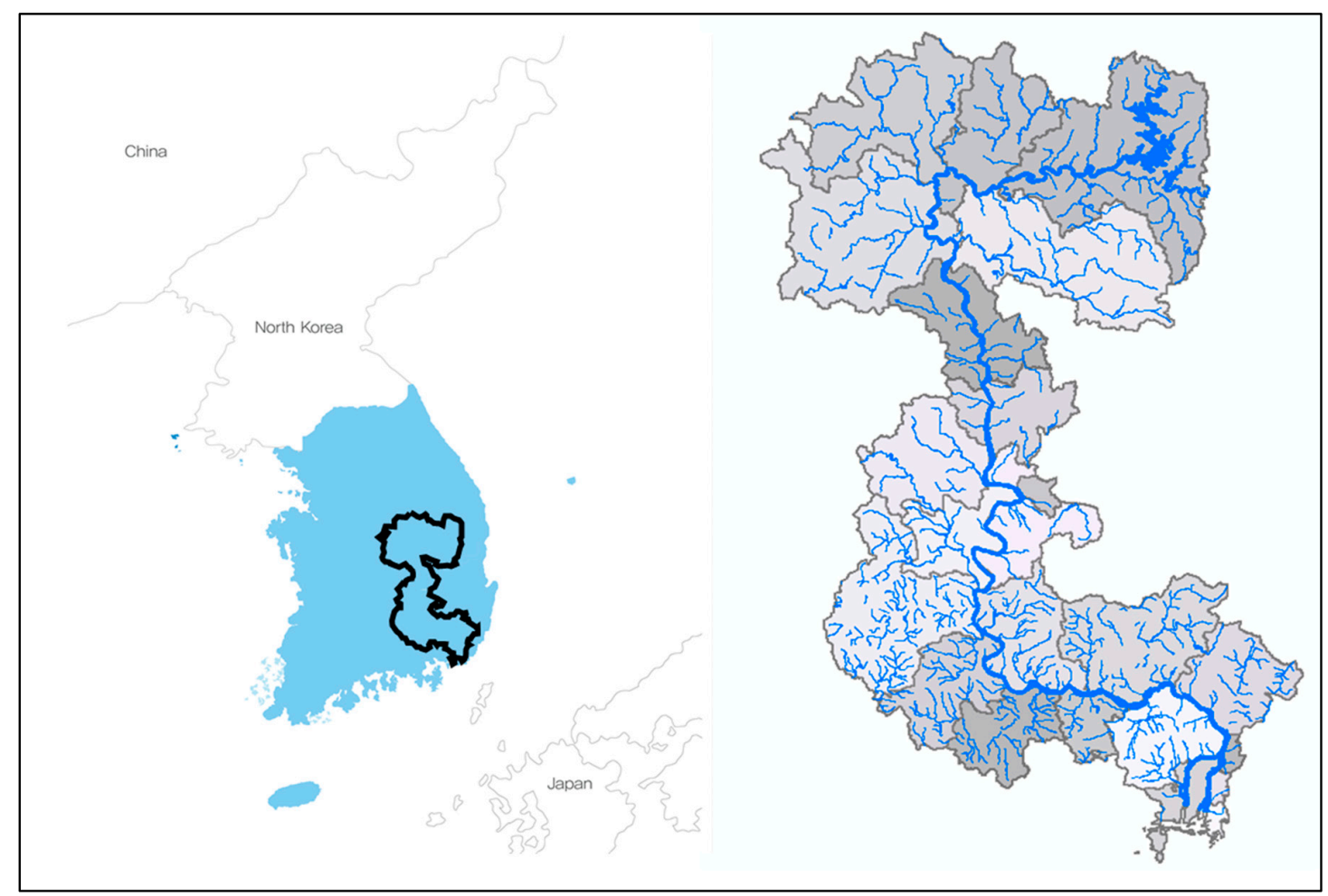

Figure 2. Location of the Nakdong River Basin.

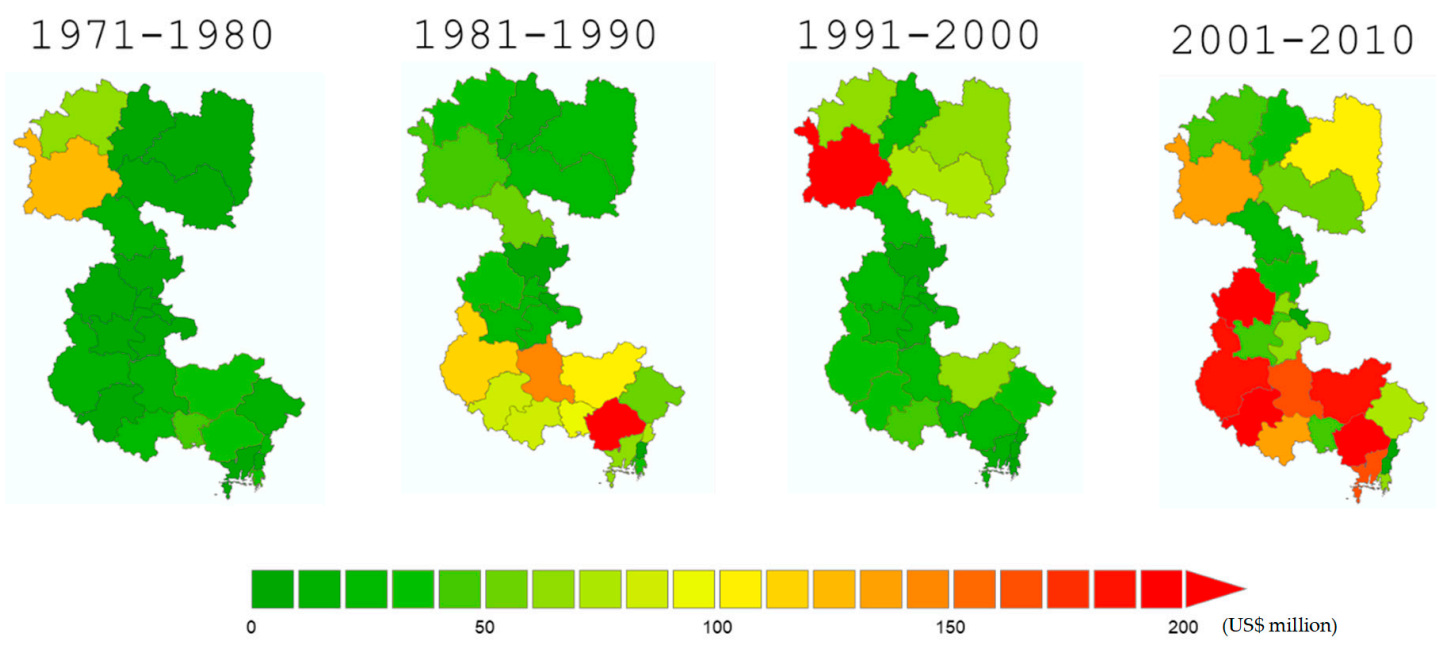

Figure 3. Ten-year sum of flood damage costs considering the inflation rate in the 23 local municipalities in the Nakdong River Basin between 1971 and 2010 (US\$ million).

\subsection{Case Study Conditions and Input Parameters}

To establish adaptation plans for future floods, we needed to determine the expanding capacity of the FCFs. According to the RCP climate scenarios, the annual precipitation in the Nakdong River Basin will increase to the year of 2100 [28]. Because of the insufficient capacity of existing FCFs, flood damage is anticipated to increase in all of the 23 local municipalities. RCP8.5 is the so-called "baseline" scenario that does not contain any climate mitigation targets [31] and RCP4.5 is a stabilization scenario involving the obligation of reducing GHG emissions [32]. Thus, to analyze future climate risk, we used the RCP4.5 and RCP8.5 climate scenarios for the case site in the Nakdong River Basin. 
It is important to identify economic parameters to determine the economic feasibility of the investment projects [16]. The historical precipitation data and damage costs from floods came from records obtained from 1986 to 2015 for the 23 local municipalities. The precipitation data and historical damage costs were used to estimate future damage costs under the selected climate scenarios. The risk-free rate, the inflation rate, and the risk-adjusted discount rate were assumed to be $5 \%$ per year, $3 \%$ per year, and $13 \%$ per year, respectively. The annual operation and maintenance (O\&M) costs were assumed to be a yearly $3 \%$ of the damage costs in the case of a flood occurrence. We assumed the project period of the case study to be from 2017 to 2100 .

The river basins in South Korea did not have sufficient FCFs to prevent precipitation-induced floods. In 2016, the central government decided to invest US $\$ 8.7$ billion, until 2020, for adaptation measures to avoid damage by future floods [33]. The adaptation measures include the installation of FCFs with a design level corresponding to floods with a 200-year return period. However, the climate scenarios of RCP4.5 and RCP8.5 show that extreme precipitation above the design level will occur in many of the local municipalities in the case study. Higher precipitation increases than those in the past, as well as regional differences, are remarkable [22]. Figure 4 shows the anticipated precipitation change rate from 2041 and 2070, as well as from 2071 and 2100, based on the 10-year average, from 2001 to 2010 , under RCP4.5 and RCP8.5.

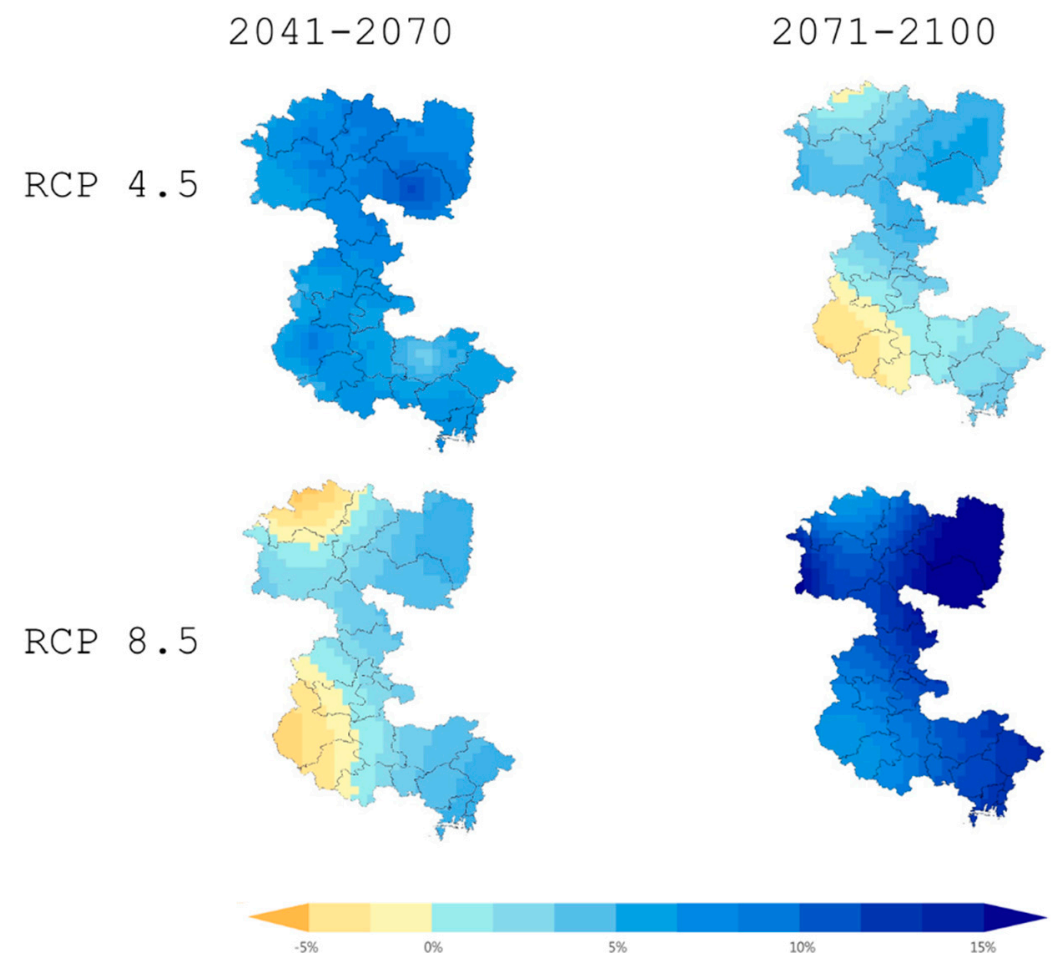

Figure 4. Change rates of annual precipitation under RCP4.5 and RCP8.5.

An initial cost of US $\$ 2$ billion was invested in 2017. We determined the execution timing of the expansion option based on the RCP climate scenarios projecting the frequency and the intensity of future extreme weather events. After 2040, many extreme floods will occur. For example, RCP4.5 projects 37 flooding events that will exceed the design criteria of the 200-year return period, until 2100. In Uiseong-gun, one of the case sites, the year 2083 presents an extreme rainfall event of $671.8 \mathrm{~mm}$ in a 48-h period, which is half of the annual precipitation under the RCP4.5 scenario. RCP8.5 shows 65 floods that exceed the design standard. In Saha-gu, Busan, another case site, an extreme rainfall event of $1100.9 \mathrm{~mm}$ in a 48 -hr period is projected to occur in 2097. This precipitation is equal to the total annual precipitation at this site. US $\$ 17.5$ billion for the expansion option in 2040 is assumed to 
be able to prevent up to five times as much future damage to the existing facility. This case study analyzed the expansion option. Table 1 lists the input parameters used in the analysis.

Table 1. Input parameters of the case study.

\begin{tabular}{cc}
\hline Parameter & Value \\
\hline Case study site & 23 local municipalities in the Nakdong River Basin \\
Risk-free rate & $5.0 \% /$ year \\
Inflation rate & $3.0 \% /$ year \\
Yearly O\&M costs & $3 \%$ of the damage costs \\
Climate scenarios & RCP4.5/8.5 \\
Project period & between 2017 and 2100 \\
Option type & Expansion option \\
Initial investment costs in 2017 & US $\$ 2$ billion \\
Second investment costs for expansion in 2040 & US $\$ 17.5$ billion \\
\hline
\end{tabular}

\section{Results and Discussion}

\subsection{Future Damage Costs}

Using the relationship between damage cost and return period of a flood, the future damage costs in the 23 municipalities were estimated. For Goryeong-gun, the equation of the log-linear relationships between damage cost and return period is the transformation of Equation (1), as follows: $D_{i}=12,915,270.7211 \ln (R)(1+0.03)^{i-1}$. The damage resulting from each extreme weather event was derived from the specified equation for each local municipal area. In order to estimate the trend line for calculating future damage costs in the case study areas, we used historical rainfall data and damage data in the case study area from 1986 to 2015. The points in Figure 5 represent past flood events, and the trend line shows the log-linear relationship between the biggest damage cost and the corresponding return period for a site. Future damage cost can be estimated by each equation of the log-linear relationship of the 23 municipalities, where each equation is a modification of Equation (1). Figures 6 and 7 show the damage costs in the 23 municipalities under RCP4.5 and RCP8.5, respectively. Damage from flood events under the RCP scenarios are anticipated to rapidly increase after 2040. Appendixs A and B show damage costs projected under RCP4.5, and 8.5, respectively. 

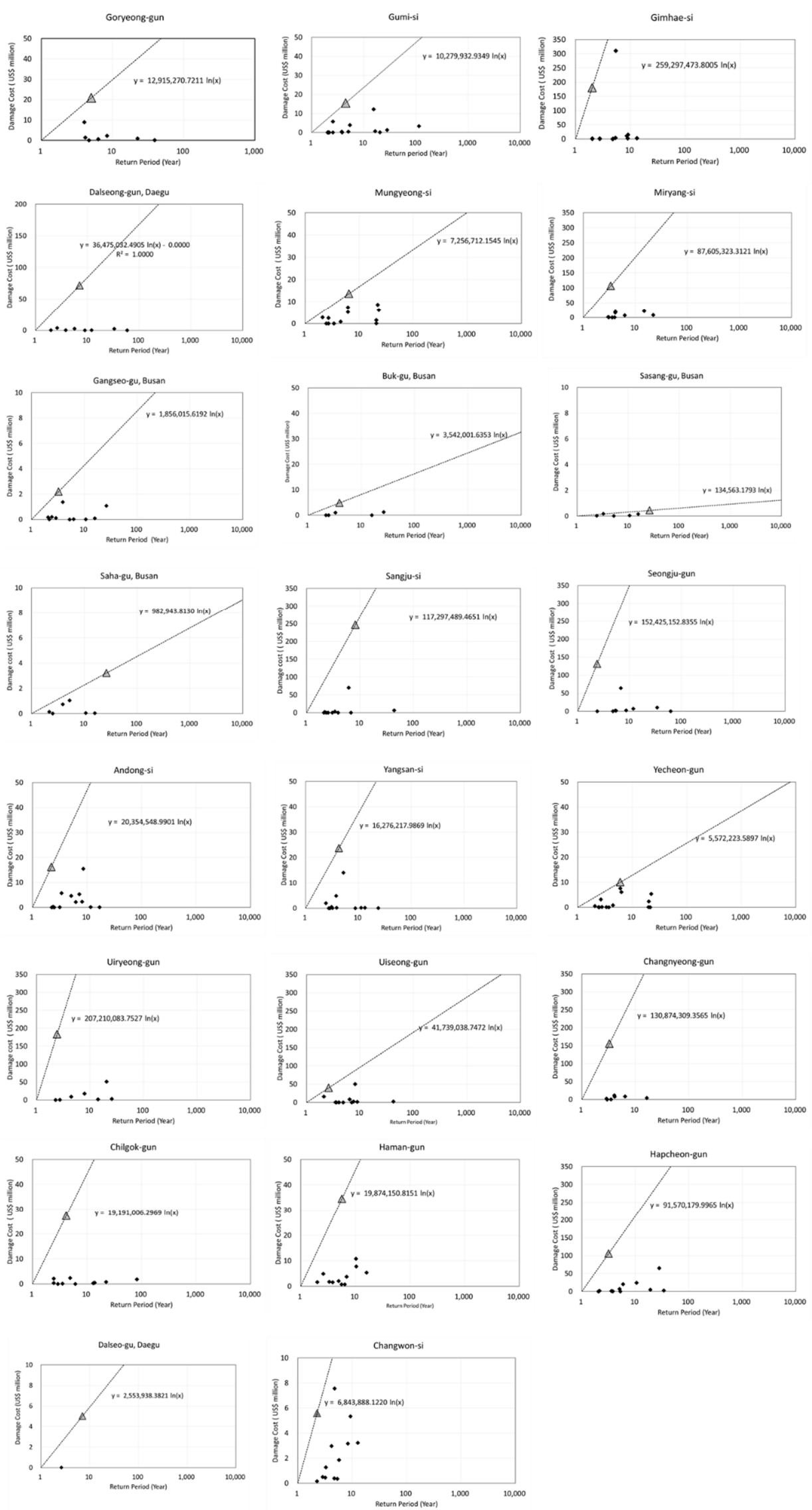

Figure 5. Relationship of historical damage cost and return period in the 23 municipalities in the Nakdong River Basin. 


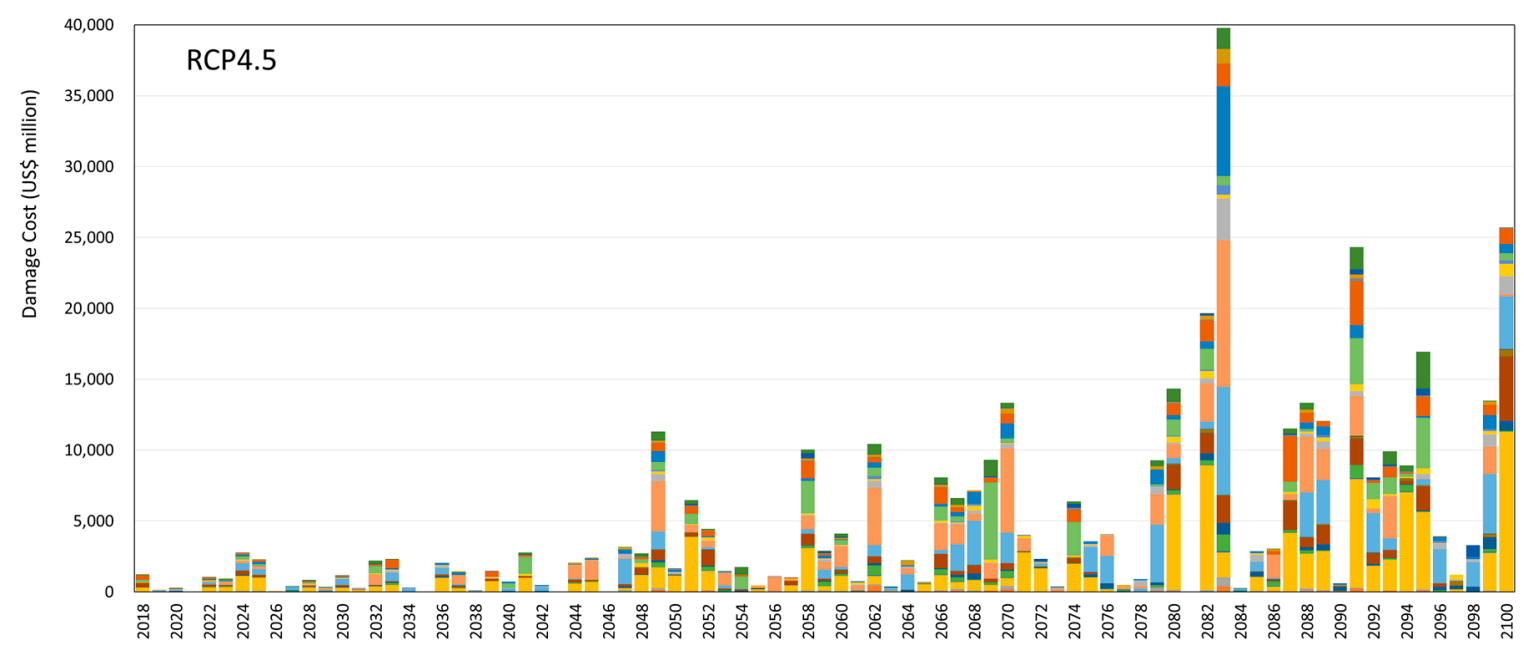

\begin{tabular}{|c|c|c|c|c|c|}
\hline Goryeong-gun & Gumi-si & $\square$ Gimhae-si & Dalseo-gu, Daegu & \multicolumn{2}{|c|}{ Dalseong-gun, Daegu $\square$ Mungyeong-si } \\
\hline Miryang-si & Eangseo-gu, Busan & " Buk-gu, Busan & Sasang-gu, Busan & - Saha-gu, Busan & Wangju-si \\
\hline Seongju-gun & $\square$ Andong-si & Yangsan-si & Yecheon-gun & E Uiryeong-gun & E Uiseong-gun \\
\hline Changnyeong-gun & Changwon-si & Chilgok-gun & Haman-gun & Hapcheon-gun & \\
\hline
\end{tabular}

Figure 6. Future damage between 2018 and 2100 under the RCP4.5 scenario.

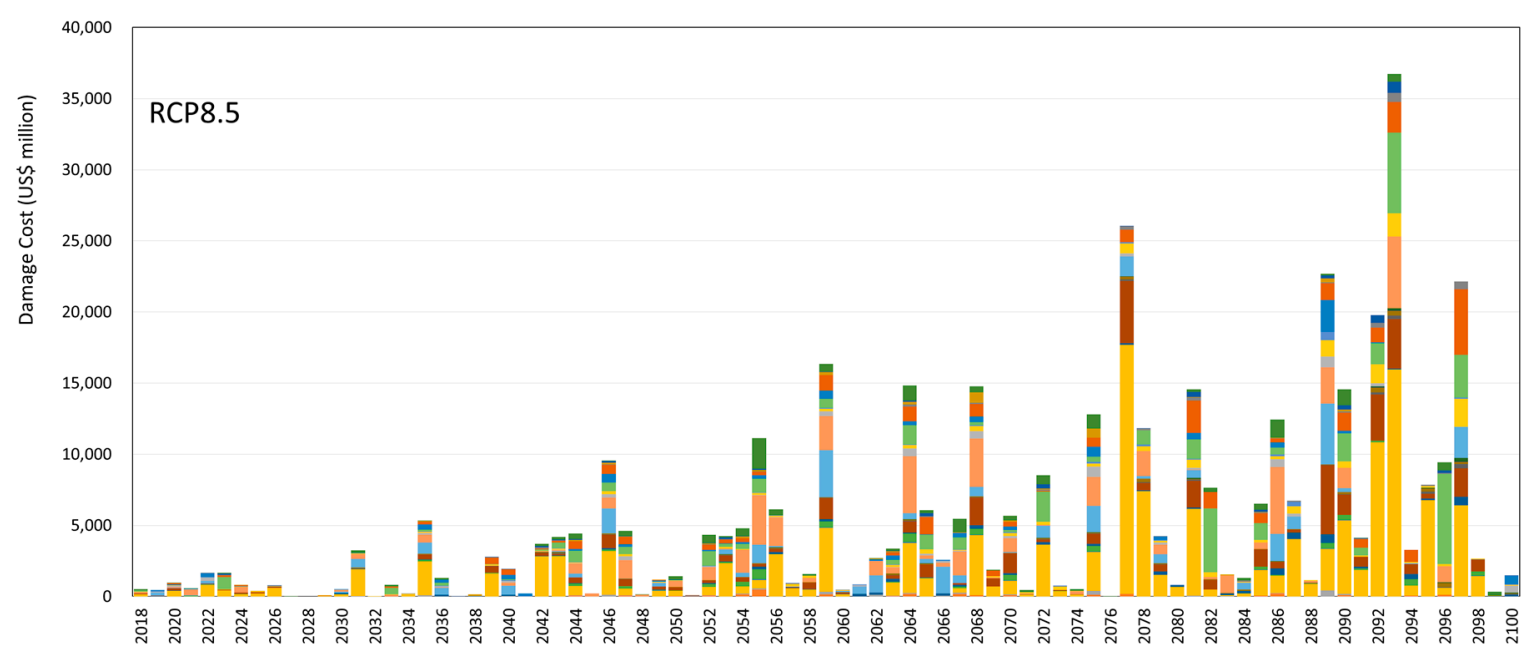

\begin{tabular}{|c|c|c|c|c|c|}
\hline — Goryeong-gun & @ Gumi-si & $\llbracket$ Gimhae-si & Dalseo-gu, Daegu & Dalseong-gun, D & a Mungyeong-si \\
\hline Miryang-si & I Gangseo-gu, Busan & Buk-gu, Busan & - Sasang-gu, Busan & - Saha-gu, Busan & = Sangju-si \\
\hline 『 Seongju-gun & Andong-si & $\square$ Yangsan-si & -Yecheon-gun & — Uiryeong-gun & - Uiseong-gun \\
\hline Changnyeong-gun & - Changwon-si & Chilgok-gun & - Haman-gun & Hapcheon-gun & \\
\hline
\end{tabular}

Figure 7. Future damage between 2018 and 2100 under the RCP8.5 scenario.

\subsection{Decision Making on an Adaptation Strategy}

Using Equation (2), the volatilities were calculated to be $41.6 \%$ and $29.2 \%$, under RCP4.5 and 8.5 , respectively. This means that the intensity and frequency of floods is more severe under RCP4.5 than under RCP8.5. The present values of the underlying assets and NPVs were estimated using Equations (3) and (4), respectively (Table 2). The option values were estimated using Equation (5). 
The expansion option can be exercised at any time, up until the expiration year of 2040. Appendixs C and D show the binomial lattices that illustrate the option values under the RCP4.5 and RCP8.5 climate scenarios, respectively. The result of the option value is US\$4.8 billion, and the NPV is - US $\$ 6.9$ billion in 2017 under RCP4.5. In view of a traditional economic assessment, the negative NPV means that the project is not feasible. However, the project value was improved by the expansion option, and the difference between the option value and the NPV is the added value by holding the right of real options. Local municipalities can decide whether or not to invest in the expansion project if the RCP4.5 climate scenario occurs. The result of the case study is thus demonstrated to be feasible. Similarly, the result of RCP8.5 denotes that the expansion option is available in this case study. Table 2 lists the volatility, option value, and NPV, under each RCP climate scenario.

Table 2. Results of the real options analysis (ROA) under representative concentration pathway RCP4.5 and RCP8.5.

\begin{tabular}{ccc}
\hline Result & RCP4.5 & RCP8.5 \\
\hline Volatility & $41.6 \%$ & $29.2 \%$ \\
Option value & US $\$ 4.8$ billion & US $\$ 4.8$ billion \\
Net present value (NPV) & - US $\$ 6.9$ billion & - US $\$ 6.7$ billion \\
\hline
\end{tabular}

Under the RCP scenarios, the 23 municipalities in the Nakdong River Basin are anticipated to face more severe floods. Thus, the expansion of FCFs should be invested in. By ROA, we believe that it is economically feasible to exercise the expansion option of an investment of US\$17.6 billion in 2040. The monetary profits occur from avoiding flood damage through an investment in the expansion option. By analyzing the damage costs, we prioritized the higher-risk municipal governments. Gimhae-si is the most vulnerable to floods, and the cumulative damage costs are US\$101 billion until 2100. The damage in Gimhae-si is approximately 100 times the damage of Sasna-gu in Busan. Municipalities should investigate future climate risks when establishing an investment plan for FCF projects. Holding options secures the economic feasibility of adaptation projects under CC. The findings of this case study will help local municipalities establish proactive investment plans for FCF projects.

This study had limitations that can be improved upon through future research. First, the case study did not explain the type and level of design criteria for the FCF under each RCP climate scenario. In a future study, analyzing the level of the flood events in each municipality could allow for the proposal of detailed adaptation design standards. Secondly, the study did not investigate the interaction of upstream and downstream on the Nakdong River in the case of extreme flood events. Hydrological analysis by advanced methodologies in future studies will upgrade the level of assessment of flood damage for each municipality in the Nakdong River Basin. Third, using more scenarios would give a better idea of the sensitivity of the FCFs across a range and their robustness over time. This enables the decision-maker to assess the flexibility of the FCFs chosen to accommodate changed flood frequency and magnitude over time. However, here, we only used the RCP4.5 and RCP8.5 scenarios to represent two plausible future conditions, for the purposes of testing the ROA methodology in the case study. In real-life decision situations, a wider range of $\mathrm{CC}$ and socio-economic scenarios would be used for testing robustness and flexibility of FCFs.

\section{Conclusions}

The objective of this study was to propose a framework to suggest an adaptation investment for FCFs of a flood zone under CC. The framework is a real option-based tool to assess the economic feasibility and suggest investment priorities in multiple municipalities for adaptation to CC. The framework shows the damage costs and option values of the municipalities in a flood zone. Each damage cost was determined using the log-linear relationship between the highest damage cost and the corresponding return period for a site, under each future climate scenario. A case study of the Nakdong River Basin of South Korea was conducted, to demonstrate the ability of the framework, 
to determine the economic feasibility for an adaptation investment considering future climate scenarios (RCP4.5/8.5). Through an expansion option, the project value improved in the case study, which included the 23 municipalities in the Nakdong River Basin. The damage costs from 2018 to 2100 were estimated, using a log-linear relationship between damage and the return period of a flood event, under RCP4.5 and 8.5 climate scenarios. The volatility showed the fluctuation of the future flood damage under CC. The level of damage costs indicated the priority of the investment. To reduce climate uncertainties, investment decision-holding options will provide more financial feasibility. The results of the case study showed that investments in the FCFs of the 23 municipalities in the Nakdong River Basin under RCP4.5 and 8.5 scenarios were feasible.

This paper proposed a framework to assess the economic feasibility of FCF projects in multiple municipalities under CC. The contribution of our study to the current body of knowledge is two-fold. First, the proposed economic assessment framework supports local municipalities in estimating future damage costs through the projection of RCP climate scenarios. Second, the ROA improves the level of economic assessment for proactive adaptation plans where there are uncertainties. Managerial flexibility, such as an expansion option, improves the profitability of FCF projects under climate scenarios. The proposed economic assessment framework will assist policy-makers in planning adaptation investment strategies to cope with climate-related risks.

Acknowledgments: This research was supported by Korea Institute of Construction Technology (Project name: Development of Floodplain Maintenance Technology for Enhancement of Waterfront Values, Project number: 2017-0100) and by the Yonsei University Research Fund (Post Doc. Researcher Supporting Program) of 2017 (project number: 2017-12-0032). We also thank the anonymous reviewers for their valuable comments, which greatly improved the manuscript.

Author Contributions: Kyeongseok Kim and Ji-Sung Kim designed the research and wrote the paper; Kyeongseok Kim collected data; Ji-Sung Kim contributed to progress of research idea; all authors have read and approved the final manuscript.

Conflicts of Interest: The authors declare no conflict of interest. 


\section{Appendix A}

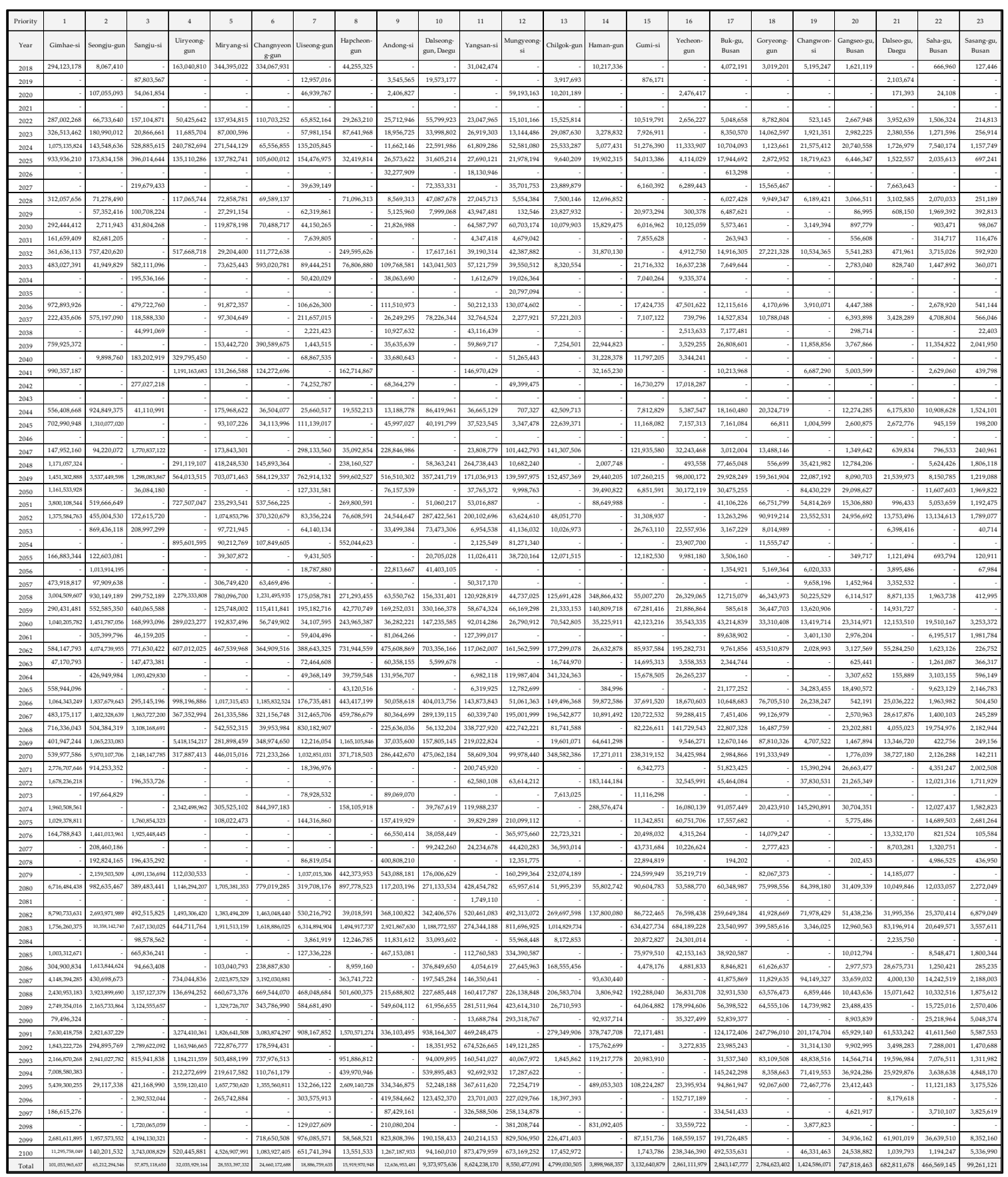

Figure A1. The damage costs projected under RCP4.5. 


\section{Appendix B}

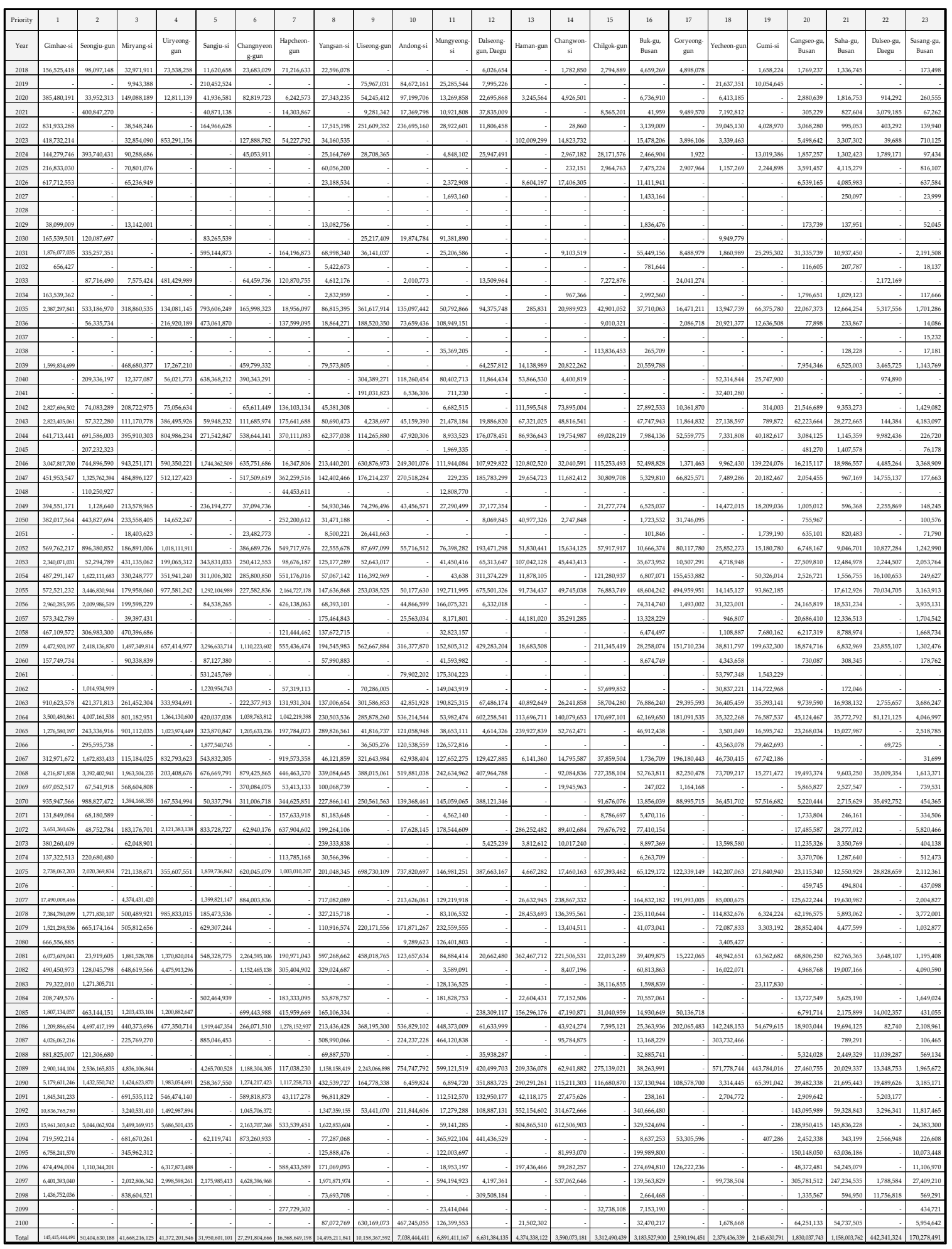

Figure A2. The damage costs projected under RCP8.5. 


\section{Appendix C}

RCP4.5

ROA of the case study project (in US\$ billion)

\begin{tabular}{clll|} 
Year & 2016 & 2021 & 2041 \\
\hline Asset value & & \\
\hline
\end{tabular}

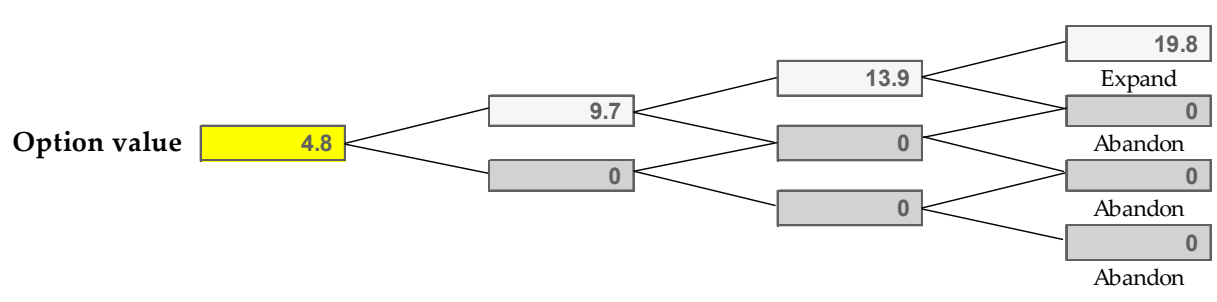

Figure A3. The binomial lattice of ROA under RCP4.5.

\section{Appendix D}

RCP8.5

ROA of the case study project (in US\$ billion)

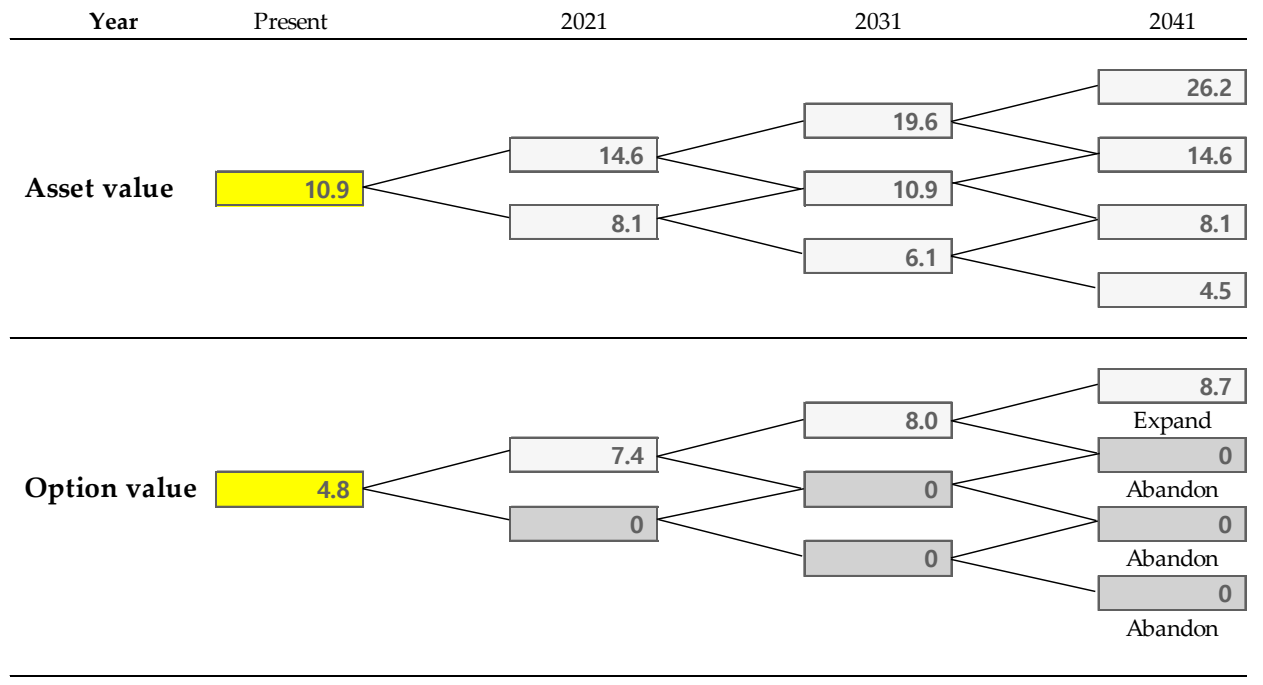

Figure A4. The binomial lattice of ROA under RCP8.5.

\section{References}

1. Knight, K.; Schor, J. Economic Growth and Climate Change: A Cross-National Analysis of Territorial and Consumption-Based Carbon Emissions in High-Income Countries. Sustainability 2014, 6, 3722. [CrossRef]

2. Intergovernmental Panel on Climate Change (IPCC). Climate Change 2014: Synthesis Report; Intergovernmental Panel on Climate Change (IPCC): Geneva, Switzerland, 2014. 
3. Ha, S.; Kim, H.; Kim, K.; Lee, H.; Kim, H. Algorithm for Economic Assessment of Infrastructure Adaptation to Climate Change. Natl. Hazards Rev. 2017, 18, 04017007. [CrossRef]

4. Trærup, S.; Stephan, J. Technologies for adaptation to climate change. Examples from the agricultural and water sectors in Lebanon. Clim. Chang. 2015, 131, 435-449. [CrossRef]

5. Arnbjerg-Nielsen, K.; Fleischer, H. Feasible adaptation strategies for increased risk of flooding in cities due to climate change. Water Sci. Technol. 2009, 60, 273-281. [CrossRef] [PubMed]

6. Zhou, Q.; Mikkelsen, P.S.; Halsnæs, K.; Arnbjerg-Nielsen, K. Framework for economic pluvial flood risk assessment considering climate change effects and adaptation benefits. J. Hydrol. 2012, 414-415, 539-549. [CrossRef]

7. Olsen, A.S.; Zhou, Q.; Linde, J.J.; Arnbjerg-Nielsen, K. Comparing methods of calculating expected annual damage in urban pluvial flood risk assessments. Water 2015, 7, 255-270. [CrossRef]

8. Ha, S.; Kim, K.; Kim, K.; Jeong, H.; Kim, H. Reliability Approach in Economic Assessment of Adapting Infrastructure to Climate Change. J. Manag. Eng. 2017, 33, 04017022. [CrossRef]

9. Kim, K.; Park, H.; Kim, H. Real options analysis for renewable energy investment decisions in developing countries. Renew. Sustain. Energy Rev. 2017, 75, 918-926. [CrossRef]

10. Kim, K.; Park, T.; Bang, S.; Kim, H. Real Options-Based Framework for Hydropower Plant Adaptation to Climate Change. J. Manag. Eng. 2017, 33, 04016049. [CrossRef]

11. Trigeorgis, L. Real Options: Managerial Flexibility and Strategy in Resource Allocation; The MIT Press: Cambridge, MA, USA, 1996.

12. Kim, Y.; Shin, K.; Ahn, J.; Lee, E.-B. Probabilistic Cash Flow-Based Optimal Investment Timing Using Two-Color Rainbow Options Valuation for Economic Sustainability Appraisement. Sustainability 2017, 9, 1781. [CrossRef]

13. Dai, H.; Sun, T.; Guo, W. Brownfield Redevelopment Evaluation Based on Fuzzy Real Options. Sustainability 2016, 8, 170. [CrossRef]

14. Ryu, Y.; Kim, Y.-O.; Seo, S.B.; Seo, I.W. Application of real option analysis for planning under climate change uncertainty: A case study for evaluation of flood mitigation plans in Korea. Mitig. Adapt. Strateg. Glob. Chang. 2017. [CrossRef]

15. Kontogianni, A.; Tourkolias, C.H.; Damigos, D.; Skourtos, M. Assessing sea level rise costs and adaptation benefits under uncertainty in Greece. Environ. Sci. Policy 2014, 37, 61-78. [CrossRef]

16. Kim, K.; Ha, S.; Kim, H. Using real options for urban infrastructure adaptation under climate change. J. Clean. Prod. 2017, 143, 40-50. [CrossRef]

17. Gersonius, B.; Ashley, R.; Pathirana, A.; Zevenbergen, C. Climate change uncertainty: Building flexibility into water and flood risk infrastructure. Clim. Chang. 2013, 116, 411-423. [CrossRef]

18. Woodward, M.; Kapelan, Z.; Gouldby, B. Adaptive flood risk management under climate change uncertainty using real options and optimization. Risk Anal. 2014, 34, 75-92. [CrossRef] [PubMed]

19. Harrison, G.P.; Whittington, H.; Wallace, A.R. Climate change impacts on financial risk in hydropower projects. IEEE Trans. Power Syst. 2003, 18, 1324-1330. [CrossRef]

20. Ministry of the Interior and Safety (MOIS). Yearbook of Disasters (in Korean); Ministry of the Interior and Safety: Sejong-si, Korea, 2017.

21. Jeong, H.; Kim, H.; Kim, K.; Kim, H. Prediction of Flexible Pavement Deterioration in Relation to Climate Change Using Fuzzy Logic. J. Infrastruct. Syst. 2017, 23, 04017008. [CrossRef]

22. Kim, K.; Jeong, H.; Ha, S.; Bang, S.; Bae, D.-H.; Kim, H. Investment timing decisions in hydropower adaptation projects using climate scenarios: A case study of South Korea. J. Clean. Prod. 2017, 142, 1827-1836. [CrossRef]

23. Mun, J. Real Options Analysis: Tools and Techniques for Valuing Strategic Investments and Decisions, 2nd ed.; John Wiley \& Sons: Hoboken, NJ, USA, 2002; Volume 137.

24. Kodukula, P.; Papudesu, C. Project Valuation Using Real Options: A practitioner's Guide; J. Ross Publishing: Fort Lauderdale, FL, USA, 2006.

25. Mayer, C.; Breun, P.; Schultmann, F. Considering risks in early stage investment planning for emission abatement technologies in large combustion plants. J. Clean. Prod. 2017, 142 Pt 1, 133-144. [CrossRef]

26. Copeland, T.E.; Antikarov, V. Real Options: A Practitioner's Guide, 2nd ed.; Cengage Learning: New York, NY, USA, 2003.

27. Loncar, D.; Milovanovic, I.; Rakic, B.; Radjenovic, T. Compound real options valuation of renewable energy projects: The case of a wind farm in Serbia. Renew. Sustain. Energy Rev. 2017, 75, 354-367. [CrossRef] 
28. Korea Meteorological Administration (KMA). Climate Change Forecast for the Korean Peninsula; Korea Meteorological Administration (KMA): Seoul, Korea, 2013.

29. Ministry of Land, Infrastructure and Transport (MOLIT). Information of Nakdong River Basin; Han River Flood Control Office: Seoul, Korea, 2017.

30. Ministry of Land, Infrastructure and Transport (MOLIT). Study for Improvement and Supplementation of Design Rainfall; Ministry of Land, Infrastructure and Transport: Sejong, Korea, 2011.

31. Riahi, K.; Rao, S.; Krey, V.; Cho, C.; Chirkov, V.; Fischer, G.; Kindermann, G.; Nakicenovic, N.; Rafaj, P. RCP 8.5-A scenario of comparatively high greenhouse gas emissions. Clim. Chang. 2011, 109, 33-57. [CrossRef]

32. Thomson, A.M.; Calvin, K.V.; Smith, S.J.; Kyle, G.P.; Volke, A.; Patel, P.; Delgado-Arias, S.; Bond-Lamberty, B.; Wise, M.A.; Clarke, L.E.; et al. RCP4.5: A pathway for stabilization of radiative forcing by 2100. Clim. Chang. 2011, 109, 77-94. [CrossRef]

33. Ministry of Land, Infrastructure and Transport (MOLIT). Longterm Plan of Water Resource (2001-2020); Ministry of Land, Infrastructure and Transport: Sejong-si, Korea, 2016.

(C) 2018 by the authors. Licensee MDPI, Basel, Switzerland. This article is an open access article distributed under the terms and conditions of the Creative Commons Attribution (CC BY) license (http:/ / creativecommons.org/licenses/by/4.0/). 